\title{
Neonatal Alexander Disease : Novel GFAP Mutation and Comparison to Previously Published Cases
}

\section{Knuutinen, Oula}

2018-08

Knuutinen , O , Kousi , M , Suo-Palosaari , M , Moilanen , J S , Tuominen , H , Vainionpää , L , Joensuu , T , Anttonen , A-K , Uusimaa , J , Lehesjoki , A-E \& Vieira , P 2018 , ' Neonatal Alexander Disease : Novel GFAP Mutation and Comparison to Previously Published Cases ' , Neuropediatrics , vol. 49 , no. 4 , pp. 256-261 . https://doi.org/10.1055/s-0038-1649500

http://hdl.handle.net/10138/309567

https://doi.org/10.1055/s-0038-1649500

unspecified

acceptedVersion

Downloaded from Helda, University of Helsinki institutional repository.

This is an electronic reprint of the original article.

This reprint may differ from the original in pagination and typographic detail.

Please cite the original version. 


\section{Neonatal Alexander disease: novel GFAP mutation and comparison to previously}

\section{published cases}

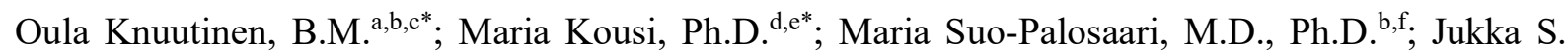

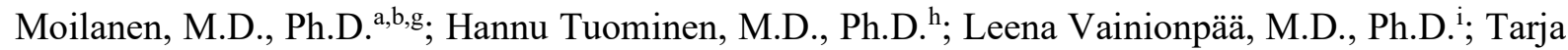
Joensuu, Ph.D. ${ }^{\mathrm{d}, \mathrm{j}, \mathrm{k}}$, Anna-Kaisa Anttonen, M.D., Ph.D. ${ }^{\mathrm{d}, \mathrm{j}, \mathrm{k}, \mathrm{l}}$, Johanna Uusimaa, M.D., Ph.D. ${ }^{\mathrm{a}, \mathrm{b}, \mathrm{c}, \mathrm{i}}$;

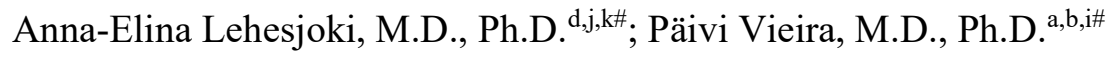

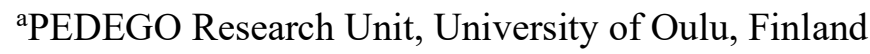

${ }^{\mathrm{b}}$ Medical Research Center Oulu, Oulu University Hospital and University of Oulu, Finland

${ }^{\mathrm{c} B i o c e n t e r}$ Oulu, University of Oulu, Finland

${ }^{\mathrm{d}}$ Folkhälsan Institute of Genetics, Helsinki, Finland

${ }^{\mathrm{e}}$ Center for Human Disease Modeling, Duke University Medical Center, Durham, NC, USA

fDepartment of Diagnostic Radiology, Oulu University Hospital, Finland

${ }^{g}$ Department of Clinical Genetics, Oulu University Hospital, Finland

${ }^{\mathrm{h}}$ Department of Pathology, Cancer and Translational Medicine Research Unit, University of Oulu and Oulu University Hospital, Finland

${ }^{\mathrm{i}}$ Clinic for Children and Adolescents, Oulu University Hospital, Finland

${ }^{\mathrm{j} N e u r o s c i e n c e ~ C e n t e r, ~ U n i v e r s i t y ~ o f ~ H e l s i n k i, ~ F i n l a n d ~}$

${ }^{k}$ Research Programs Unit, Molecular Neurology, University of Helsinki, Finland

${ }^{1}$ Medical and Clinical Genetics, University of Helsinki and Helsinki University Hospital, Finland

* Knuutinen and Kousi contributed equally (first author)

${ }^{\#}$ Lehesjoki and Vieira contributed equally (senior author)

Corresponding author:

Päivi Vieira, Clinic for Children and Adolescents, Oulu University Hospital, PO Box 23, 90029 Oulu, Finland. paivi.vieira@fimnet.fi. Tel+35883155245, Fax +35883155545.

The work was carried out at Oulu University Hospital, University of Oulu and University of Helsinki.

Neuropediatrics 2018; 49(04): 256-261. DOI: 10.1055/s-0038-1649500

(C) Copyright 2019, Thieme Medical Publishers, Inc. 


\begin{abstract}
Alexander disease $(\mathrm{AxD})$ is a genetic leukodystrophy caused by GFAP mutations leading to astrocyte dysfunction. Neonatal AxD is a rare phenotype with onset in the first month of life. The proband, belonging to a large pedigree with dominantly inherited benign familial neonatal epilepsy (BFNE), had a phenotype distinct from the rest of the family, with hypotonia and macrocephaly in addition to drug-resistant neonatal seizures. The patient deteriorated and passed away at 6 weeks of age. The pathological and neuroimaging data were consistent with the diagnosis of AxD. Genetic analysis of the proband identified a novel de novo GFAP missense mutation and a $K C N Q 2$ splice site mutation segregating with the BFNE phenotype in the family. The GFAP mutation was located in the coil 2B region of GFAP protein, similar to most neonatal-onset AxD cases with an early death. The clinical and neuroradiological features of the previously published neonatal AxD patients are presented. This study further supports the classification of neonatal-onset Alexander disease as a distinct phenotype based on the age of onset.
\end{abstract}

Key words: drug-resistant neonatal epilepsy; hydrocephalus; neuroimaging; leukodystrophy

\title{
Introduction
}

Alexander disease (AxD; MIM 203450) is a rare leukodystrophy typically caused by heterozygous point mutations in GFAP (MIM 137780) encoding glial fibrillary acidic protein (GFAP). ${ }^{1,2}$ The mutant GFAP disrupts the normal intermediate filament network formation causing astrocyte dysfunction, reviewed $\mathrm{in}^{3}$. Abnormal astrocytic accumulations of intracytoplasmic proteinaceous inclusions, Rosenthal fibres, are characteristic of AxD. Three age-dependent clinical subtypes - 
infantile, juvenile and adult - have been recognized. ${ }^{2,4}$ The infantile subtype is the most common form manifesting with seizures, developmental delay, pyramidal tract signs and progressive

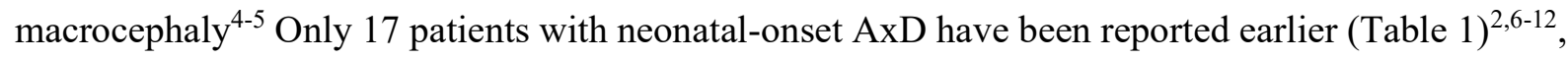
showing hypotonia and failure to thrive preceding drug-resistant seizures and macrocephaly. ${ }^{9,13}$ Neuroradiologically, extensive periventricular enhancement and white matter abnormalities of frontal predominance have been described, with involvement of the basal ganglia and cerebellum. ${ }^{10,14}$ The radiological changes can be noted already in utero. ${ }^{7}$

Mutations in KCNQ2 (MIM 602235) causing impairment of the voltage-gated potassium channel Kv7.2 lead to a wide range of epileptic phenotypes, including benign familial neonatal epilepsy (BFNE, or benign familial neonatal seizures, BFNS, MIM 121200), typically caused by autosomal dominant mutations. BFNE manifests with high frequency of seizures in the first days or weeks of life, and spontaneous remission by 6 months of age. ${ }^{15,16}$

We describe a patient with severe $\mathrm{AxD}$ of neonatal-onset, a member of a pedigree with 15 individuals affected with BFNE. The clinical and neuroradiological features of the published cases of neonatal $\mathrm{AxD}$ are reviewed.

\section{Clinical report}

The proband was a member of a Finnish family with history of neonatal seizures (unpublished, data not shown). He was born at 38 weeks of gestation by uncomplicated vaginal delivery. The Apgar scores were 5/7/7, weight $3.55 \mathrm{~kg}$, height $51 \mathrm{~cm}$ and head circumference $37.5 \mathrm{~cm}$. Drug-resistant seizures started on the fourth day of life. He did not benefit from phenobarbital, levetiracetam, topiramate or pyridoxine. The electroencephalogram (EEG) developed to burst suppression pattern by three weeks of age. The head circumference surpassed the 95th percentile at four weeks of life. 
He became lethargic with prolonged seizures and passed away at the age of six weeks. Extensive metabolic screening was normal.

The study was approved by the Regional Ethics Committee of the Northern Ostrobothnia Hospital District and Helsinki University Hospital. The guidelines of the Helsinki Declaration were followed (World Medical Association 1964). A written informed consent was obtained from the parents of the proband and the other study subjects or their parents.

\section{Radiological investigations}

Brain ultrasound was initially normal but the third and lateral ventricles dilated at two weeks of age (Fig. 1, Panel A). At the age of three weeks, magnetic resonance imaging (MRI) suggested white matter loss and hydrocephalus, caused by aqueductal stenosis due to enlargement of the tectum, and showed extensive signal abnormalities (Fig. 1, Panel B).

\section{Genetic investigations}

The proband's DNA was extracted from peripheral blood sample. The entire coding region and the highly conserved exon-intron splice junctions of GFAP were analyzed from genomic DNA by sequencing in an accredited clinical laboratory. Reference sequences were NM_001242376.1, NM_001131019.2, and NM_002055.4. Pathogenicity of the found mutation was assessed using Condel and PON-P2 prediction tools. ${ }^{17,18}$ A de novo heterozygous NM_001242376.1:c.1106T $>$ C; p.(Leu369Pro) variant located in the coil 2B area of GFAP was identified. It affects a highly conserved amino acid with in silico predictions suggesting a pathogenic effect (the Condel consensus deleteriousness score of missense mutations: $0.729(0=$ neutral, $1=$ deleterious $)$ and the PON-P2 probability for pathogenicity: 0.959 ). The variant has not been previously described and it is classified 
as likely pathogenic. ${ }^{19,20}$ The patient's DNA was also sequenced for the novel NG_009004.2(NM_172107.3):c.387+2del variant affecting the splice donor site of intron 2 of $K C N Q 2$, previously identified to segregate with the BFNE phenotype in the family (unpublished, data not shown). The variant putatively affects splicing of $K C N Q 2$ and is classified as pathogenic. ${ }^{19}$

\section{Pathological investigations}

At autopsy, the head was macrocephalic with a prominent forehead. The cerebral cortices, basal ganglia and hippocampi were symmetrically deformed. White matter was scarce and cyanotic. Lateral ventricles were dilated. Eosinophilic intracytoplasmic inclusions were most prominently present in periventricular and subpial astrocytes (Fig. 2). These inclusions were immunoreactive for GFAP and $\alpha \mathrm{B}$-crystallin consistent with the diagnosis of $\mathrm{AxD}$. Rosenthal fibers were scarce. Periventricular histopathological changes correlate with the periventricular rims seen on MRI.

\section{Discussion}

Few patients with neonatal-onset $\mathrm{AxD}$ have been described earlier (Tables 1 \& 2). We present a neonate with a novel pathogenic mutation in GFAP. Histopathology demonstrated GFAP and $\alpha \mathrm{B}-$ crystallin positive astrocytic inclusions consistent with previous reports of AxD (Fig. 2). Characteristic Rosenthal fibers and white matter signal abnormalities were not prominently present, which has been suggested to be a feature of AxD patients with very early onset. ${ }^{9}$ Among the neonatal AxD cases described earlier, the diagnostic MRI criteria developed by van der Knaap were not fulfilled in 6/17 (35\%) patients (Table 2). ${ }^{14}$ However, all six had AxD confirmed by histopathology or DNA testing. 
The proband presented typical findings of neonatal $\mathrm{AxD}$ as defined by Springer et al. and fulfills $4 / 5$ diagnostic MRI criteria. ${ }^{9}$ These include white matter abnormalities with frontal predominance, presence of a periventricular rim of decreased signal intensity on T2-weighted images and increased signal intensity on T1-weighted images, and involvement of the basal ganglia, thalami and cerebellum. The fifth criterion, contrast enhancement of the lesions, could not be assessed because the proband's young age precluded the use of contrast media. Enlarged tectum, a rarely reported feature, was noticed. ${ }^{8}$ In infantile AxD, typical MRI shows abnormal signal intensity of the frontal white matter in a symmetrical distribution. MRI of the proband had only slight changes in the white matter frontally. It may be difficult to distinguish unmyelinated white matter from abnormal white matter that may only be seen as slight hyperintensity on T2- and hypointensity on T1-weighted images. ${ }^{14}$

Canavan disease and Leigh syndrome were considered in the differential diagnosis. Similar to AxD, the thalamus and globus pallidus are typically involved in Canavan disease while the putamen and caudate nucleus are spared, and extensive cerebral white matter changes have no frontal predominance. ${ }^{21}$ The white matter and basal ganglia changes may sometimes mimic mitochondrial disorders. Symmetrical signal abnormalities of the basal ganglia, midbrain, and periventricular white matter with frontal predominance have been reported in Leigh syndrome but the periventricular rim of white matter characteristic for AxD may be spared. ${ }^{22}$

The course of the disease in the current case was rapidly progressive leading to death at the age of six weeks, which is earlier than described (Table 1 and 2).,6-12 Previous studies have associated the earlier presentation of symptoms with more severe disease progression, and a correlation between genotype and disease severity has been described. ${ }^{5,12}$ The mutation reported here affects a highly conserved amino acid residue located in the coil 2B region of GFAP, where mutations causing neonatal-onset phenotype and especially an earlier death are predominantly situated (Fig. 3, Table 1). This suggests that mutations in the coil 2B domain are more intolerable than mutations affecting other 
domains. The $K C N Q 2$ mutation, which alone was sufficient to cause neonatal seizures in the family, was most likely irrelevant for the disease course in the current case.

This study gives further support for the neonatal $\mathrm{AxD}$ as a distinct disease type based on the age of onset, and adds to the clinical and radiological phenotype of this severe disease.

\section{Acknowledgments}

We thank Prof Michael Brenner for personal communication (additional information on patients in ${ }^{2}$ ), Sara Jagodic for technical help, and Sinikka Lindh, R.N., for collecting the genealogical data. This work was supported by Folkhälsan Research Foundation. 


\section{References}

1. Brenner M, Johnson AB, Boespflug-Tanguy O, Rodriguez D, Goldman JE, Messing A. Mutations in GFAP, encoding glial fibrillary acidic protein, are associated with alexander disease. Nat Genet. 2001;27(1):117-120.

2. Li R, Johnson AB, Salomons G, et al. Glial fibrillary acidic protein mutations in infantile, juvenile, and adult forms of alexander disease. Ann Neurol. 2005;57(3):310-326.

3. Sawaishi Y. Review of alexander disease: Beyond the classical concept of leukodystrophy. Brain Dev. 2009;31(7):493-498.

4. Johnson AB, Brenner M. Alexander's disease: Clinical, pathologic, and genetic features. J Child Neurol. 2003;18(9):625-632.

5. Prust M, Wang J, Morizono H, et al. GFAP mutations, age at onset, and clinical subtypes in alexander disease. Neurology. 2011;77(13):1287-1294.

6. Meins M, Brockmann K, Yadav S, et al. Infantile alexander disease: A GFAP mutation in monozygotic twins and novel mutations in two other patients. Neuropediatrics. 2002;33(4):194-198.

7. Vazquez E, Macaya A, Mayolas N, Arevalo S, Poca MA, Enriquez G. Neonatal alexander disease: MR imaging prenatal diagnosis. AJNR Am J Neuroradiol. 2008;29(10):1973-1975.

8. Yoo IH, Hong WG, Kim H, et al. A neonatal form of alexander disease presented with intractable seizures and obstructive hydrocephalus. J Genet Med. 2013;10:113-116.

9. Springer S, Erlewein R, Naegele T, et al. Alexander disease--classification revisited and isolation of a neonatal form. Neuropediatrics. 2000;31(2):86-92. 
10. van der Knaap MS, Salomons GS, Li R, et al. Unusual variants of alexander's disease. Ann Neurol. 2005;57(3):327-338.

11. Bassuk AG, Joshi A, Burton BK, Larsen MB, Burrowes DM, Stack C. Alexander disease with serial MRS and a new mutation in the glial fibrillary acidic protein gene. Neurology. 2003;61(7):1014-1015.

12. Rodriguez D, Gauthier F, Bertini E, et al. Infantile alexander disease: Spectrum of GFAP mutations and genotype-phenotype correlation. Am J Hum Genet. 2001;69(5):1134-1140.

13. Singh N, Bixby C, Etienne D, Tubbs RS, Loukas M. Alexander's disease: Reassessment of a neonatal form. Childs Nerv Syst. 2012;28(12):2029-2031.

14. van der Knaap MS, Naidu S, Breiter SN, et al. Alexander disease: Diagnosis with MR imaging. AJNR Am J Neuroradiol. 2001;22(3):541-552.

15. Butler KM, da Silva C, Alexander JJ, Hegde M, Escayg A. Diagnostic yield from 339 epilepsy patients screened on a clinical gene panel. Pediatr Neurol. 2017;77:61-66.

16. Weckhuysen S, Mandelstam S, Suls A, et al. KCNQ2 encephalopathy: Emerging phenotype of a neonatal epileptic encephalopathy. Ann Neurol. 2012;71(1):15-25.

17. González-Pérez A, López-Bigas N. Improving the assessment of the outcome of nonsynonymous SNVs with a consensus deleteriousness score, condel. Am J Hum Genet. 2011;88(4):440-449.

18. Niroula A, Urolagin S, Vihinen M. PON-P2: Prediction method for fast and reliable identification of harmful variants. PLoS One. 2015;10(2):e0117380. 
19. Richards S, Aziz N, Bale S, et al. Standards and guidelines for the interpretation of sequence variants: A joint consensus recommendation of the american college of medical genetics and genomics and the association for molecular pathology. Genet Med. 2015;17(5):405-424.

20. Waisman Center. GFAP mutations associated with alexander disease. Available at: http://www.waisman.wisc.edu/alexander-disease/mutation-table.pdf. Accessed January 13, 201721.

21. Brismar J, Brismar G, Gascon G, Ozand P. Canavan disease: CT and MR imaging of the brain. AJNR Am J Neuroradiol. 1990;11(4):805-810.

22. Warmuth-Metz M, Hofmann E, Busse M, Solymosi L. Uncommon morphologic characteristics in leigh's disease. AJNR Am J Neuroradiol. 1999;20(6):1158-1160. 
Figure captions

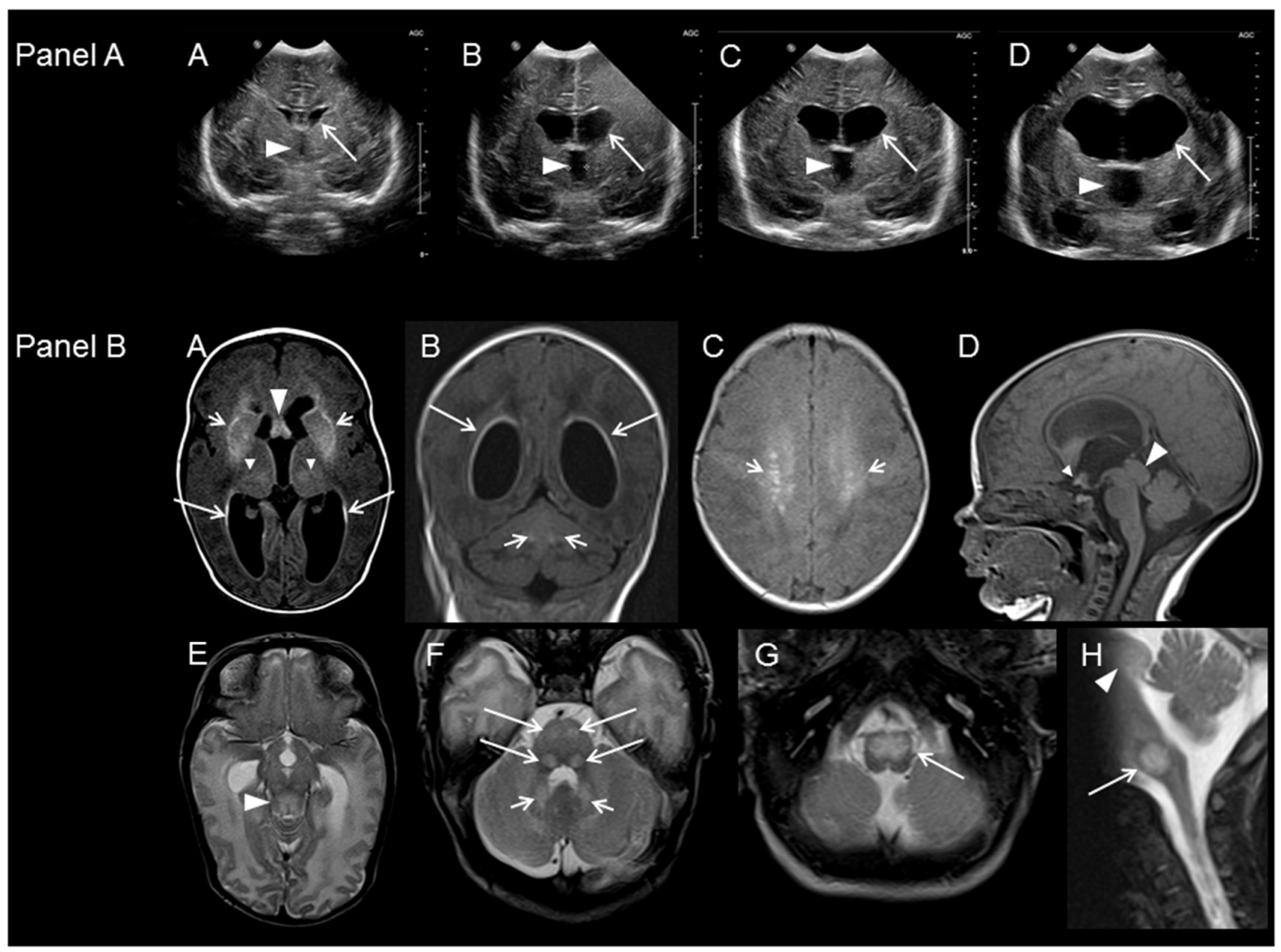

Fig. 1. Neuroimaging of the proband.

Panel A: Coronal brain ultrasound images, ages one (A), two (B), three (C) and 4.5 weeks (D), showed progressive enlargement of the lateral (arrow) and third (arrowhead) ventricles. Panel B: Brain MRI at the age of three weeks. T1-(A-D) and T2-weighted (E-H) images show characteristic findings of Alexander disease. T1-weighted images demonstrate a hyperintense periventricular rim (A and B, long arrows) and deep frontal white matter densities (C, short arrows). The basal ganglia are swollen and hyperintense (A, short arrows) and thalami are mildly T1-hyperintense (A, small arrowheads). The third and lateral ventricles are enlarged (A, B, D, E). The swollen, T2-hyperintense tectum compresses aqueduct of Sylvius (D, E and H, big arrowhead). The optic chiasm is 
hyperintense (D, small arrowhead). The fornix is thickened and hyperintense (A, big arrowhead). The hilum of dentate nucleus of the cerebellum is T1- and T2-hyperintense (B and F, short arrows). Pons (F, long arrows) and medulla ( $\mathrm{G}$ and $\mathrm{H}$, long arrow) are $\mathrm{T} 2$-hyperintense.

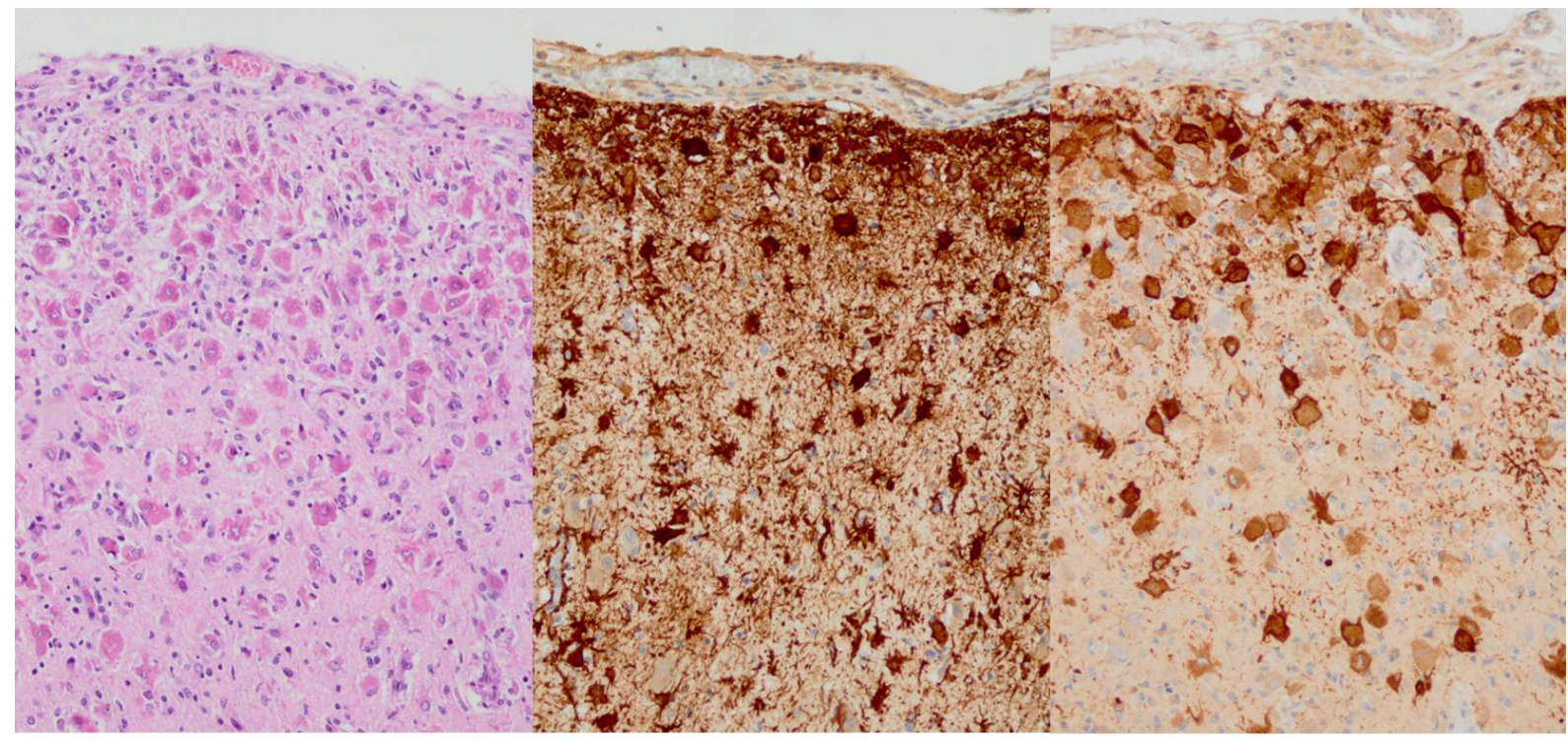
A. Hematoxylin and eosin
B. GFAP
C. aB-crystallin

Fig. 2. Histopathology of the cerebral cortex from the autopsy sample of the patient with neonatal Alexander disease.

Hematoxylin and eosin stain of the cerebral cortex (A) demonstrates eosinophilic cytoplasmic inclusions in subpial astrocytes. Immunohistochemically the material is glial fibrillary acidic protein (GFAP, B) and $\alpha \mathrm{B}$-crystallin (C) positive, which is characteristic of Alexander disease. 


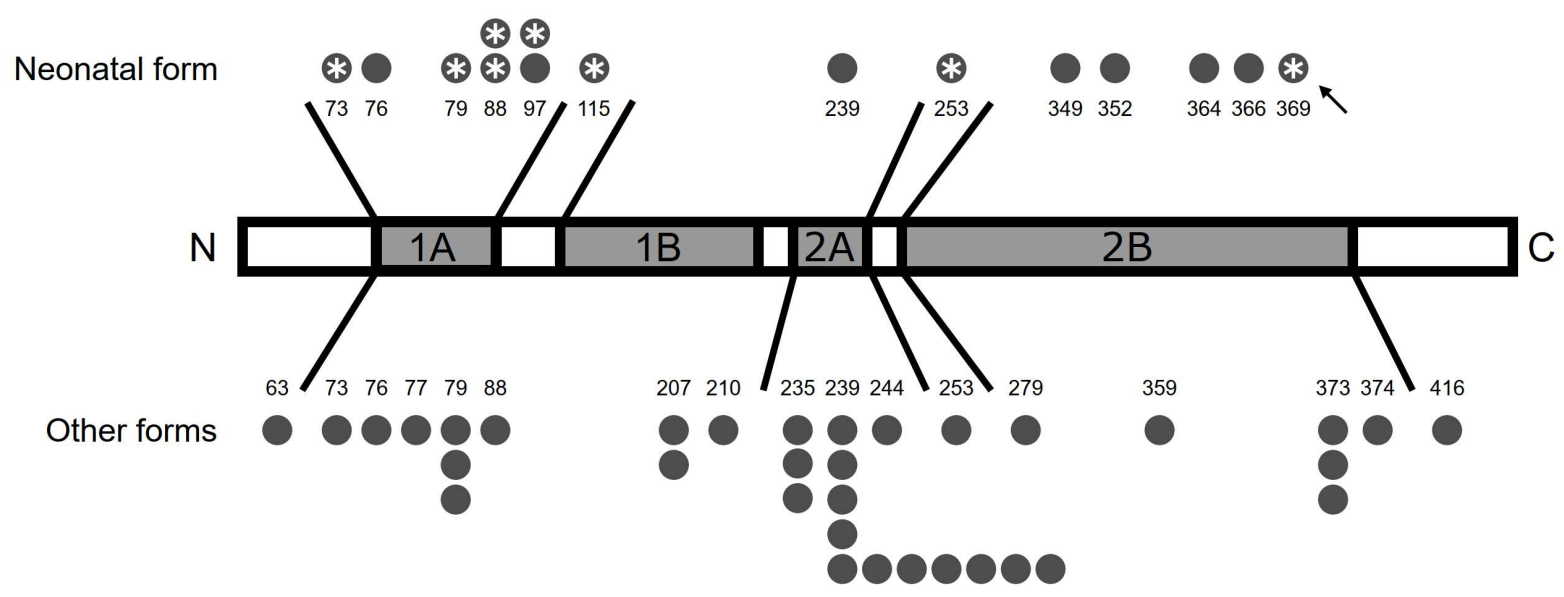

Fig. 3 Protein structure of glial fibrillary acidic protein and distribution of mutations in Alexander disease (AxD).

The $\alpha$-helical domains (grey boxes) are connected by nonhelical linker regions (white boxes). Numbers indicate the altered amino acid locations. The published mutations (circles) in neonatal AxD are shown above the protein. For reference, other forms of AxD reported by Li et al. ${ }^{2}$ are shown below, except for the neonatal cases that are above marked with an asterisk. The current case is marked with an arrow. 
Table 1. Reported cases of neonatal Alexander disease.

\begin{tabular}{|c|c|c|c|c|}
\hline \multirow[t]{2}{*}{ Reference case } & \multicolumn{3}{|l|}{ mutation } & \multirow[t]{2}{*}{ Death } \\
\hline & DNA & amino acid & protein structure & \\
\hline current case & $1106 \mathrm{~T}>\mathrm{C}$ & Leu369Pro & Coil 2B & 1.5 months \\
\hline Springer et al.$^{9}$ patient no. 1 & $\mathrm{n} / \mathrm{a}$ & $\mathrm{n} / \mathrm{a}$ & $\mathrm{n} / \mathrm{a}$ & 6 months \\
\hline Springer et al. ${ }^{9}$ patient no. 2 & $\mathrm{n} / \mathrm{a}$ & $\mathrm{n} / \mathrm{a}$ & $\mathrm{n} / \mathrm{a}$ & 20 months \\
\hline Springer et al. ${ }^{9}$ patient no. 3 & $\mathrm{n} / \mathrm{a}$ & $\mathrm{n} / \mathrm{a}$ & $\mathrm{n} / \mathrm{a}$ & 5 years \\
\hline van der Knaap et al. ${ }^{10}$ patient no. 8 & $758 \mathrm{C}>\mathrm{G}$ & Ala253Gly & Linker 2 & Alive 7 years \\
\hline van der Knaap et al. ${ }^{10}$ patient no. 10 & $343 \mathrm{G}>\mathrm{A}$ & Val115Ile & Linker 1 & 8 months \\
\hline Vazquez et al. $^{7}$ & $\mathrm{n} / \mathrm{a}$ & Met73Thr & Coil 1A & $\mathrm{n} / \mathrm{a}$ \\
\hline Li et al. ${ }^{2}$ patient no. 3 & $226 \mathrm{C}>\mathrm{T}$ & Leu76Phe & Coil 1A & 9 years \\
\hline Li et al. ${ }^{2}$ patient no. 10 & $290 \mathrm{~T}>\mathrm{C}$ & Leu97Pro & Coil 1A & 6 years 5 months \\
\hline Li et al. ${ }^{2}$ patient no. 21 & $715 \mathrm{C}>\mathrm{T}$ & Arg239Cys & Coil 2A & 2 years 5 months \\
\hline Li et al. ${ }^{2}$ patient no. 32 & & 379 HL Ins & Coil 2B & 3.5 months \\
\hline Li et al. ${ }^{2,11}$ patient no. 33 & $1055 \mathrm{~T}>\mathrm{C}$ & Leu352Pro & Coil 2B & 38 days \\
\hline Li et al. ${ }^{2}$ patient no. 35 & $1090 \mathrm{G}>\mathrm{C}$ & Ala364Pro & Coil 2B & 4 months \\
\hline Li et al. ${ }^{2}$ patient no. 36 & $1096 \mathrm{~T}>\mathrm{C}$ & Tyr366His & Coil 2B & 1.5 years \\
\hline Rodriquez et al. ${ }^{12}$ patient no. 3 & $250 \mathrm{G}>\mathrm{A}$ & Arg79His & Coil 1A & Alive 7.5 years \\
\hline Rodriquez et al. ${ }^{12}$ patient no. 8 & $276 \mathrm{C}>\mathrm{T}$ & Arg88Cys & Coil 1A & Alive 2.5 years \\
\hline Rodriquez et al. ${ }^{12}$ patient no. 9 & $276 \mathrm{C}>\mathrm{A}$ & Arg88Ser & Coil 1A & Alive 3.5 years \\
\hline Meins et al. ${ }^{6}$ patient no. 4 & $304 \mathrm{~T}>\mathrm{C}$ & Leu97Pro & Coil 1A & Alive 6 years \\
\hline
\end{tabular}


Table 2. Clinical characteristics of the published cases of neonatal Alexander disease.

\begin{tabular}{lr}
\hline & $\begin{array}{r}\text { Number of cases } \\
\text { with variable } \\
\text { adequately } \\
\text { reported }\end{array}$ \\
\hline Sex & $\begin{array}{r}10 \text { males/14 } \\
\text { median } 12 \text { mo }\end{array}$ \\
Death & $8 / 13$ \\
Death <2 years & $5 / 5$ \\
Hydrocephalus & $11 / 18$ \\
Macrocephaly & $5 / 5$ \\
Raised ICP & $13 / 14$ \\
Retardation or regression & $5 / 5$ \\
Hypotonia & $4 / 14$ \\
Spasticity & $12 / 17$ \\
Seizures & $2 / 9$ \\
Ataxia & $1 / 1$ \\
Hyperreflexia & $3 / 3$ \\
Elevated CSF protein & $11 / 12$ \\
WM abnormality & $10 / 11$ \\
Frontal WM abnormality & $8 / 9$ \\
Basal ganglia abnormality & $7 / 8$ \\
Enlarged ventricles & $7 / 8$ \\
Periventricular rim, \\
hyper- and T2-hypointense
\end{tabular}

